PNNL-11122

UC-810

Project Technical Information

\title{
Cesium Ion Exchange Using Actual Waste: Column Size Considerations
}

K. P. Brooks

April 1996

Prepared for

the U.S. Department of Energy

under Contract DE-AC06-76RLO 1830

Pacific Northwest National Laboratory

Richland, Washington 99352 
PNNL-11122

UC-810

Project Technical Information

\section{Cesium Ion Exchange Using Actual Waste: Column Size Considerations}

KP Brooks

April 1996

Prepared for

the U.S. Department of Energy

under Contract DE-AC06-76RLO 1830

Pacific Northwest National Laboratory

Richland, Washington 99352

Reprint of historical document TWRSPP-94-091, dated September 1994. Data, formatting, and other conventions reflect standards at the original date of printing. Technical peer reviews and editorial reviews may nor have been performed. 


\title{
DISCLAIMIER
}

This report was prepared as an account of work sponsored by an agency of the United States Government. Neither the United States Government nor any agency thereof, nor Battelle Memorial Institute, nor any of their employees, makes any warranty, express or implied, or assumes any legal liability or responsibility for the accuracy, completeness, or.usefulness of any information, apparatus, product, or process disclosed, or represents that its use would not infringe privately owned rights. Reference herein to any specific commercial product, process, or service by trade name, trademark, manufacturer, or otherwise does not necessarily constitute or imply its endorsement, recommendation, or favoring by the United States Government or any agency thereof, or Battelle Memorial Institute. The views and opinions of authors expressed herein do not necessarily state or reflect those of the United States Government or any agency thereof.

\section{PACIFIC NORTHWEST NATIONAL LABORATORY operated by \\ BATTELLE \\ for the \\ UNITED STATES DEPARTMENT OF ENERGY under Contract DE-ACO6-76RLO 1830}

\author{
Printed in the United States of America \\ Available to DOE and DOE contractors from the \\ nffire nf Scientisic and Terinical Information. P.O. Box 62, Oak Ridge, IN 37831 ; \\ prices available from (615) 576-8401.
}

Available to the public from the National Technical Information Service, U.S. Department of Commerce, 5285 Port Royal Rd., Springfield, VA 22161 


\section{EXECUTIVE SUMMARY}

Cesium ion exchange with actual Hanford tank waste is being planned to verify previously performed simulant runs. In order to reduce cost and radiation exposure, smaller ion exchange columns are being considered. Past studies have shown that in many cases, columns can be scaled successfully based on liquid residence time only.

The purpose of this study is to provide a theoretical foundation for sizing very small columns for actual waste testing. The study was limited to Neutralized Current Acid Waste (NCAW) and Double-Shell Slurry Feed (DSSF) wastes with Duolite* CS-100 (Rohm and Haas) and resorcinol-formaldehyde (R-F) resins. Both the column width and length were considered during scale-down. The width of the column was determined taking into consideration channelling and flow distribution. The length of the column was determined considering axial dispersion, entry length, wave shape development, mass transfer limitations, and aspect ratio. Rules of thumb, experimental results, correlations, and models were used in this development.

Minimum column dimensions are shown in Table S.1. In order to prevent significant channelling and radial gradients, the column diameter must be at least $1 \mathrm{~cm}$ and $1.9 \mathrm{~cm}$ for $\mathrm{R}-\mathrm{F}$ and $\mathrm{CS}-100$ resins, respectively. The minimum column length (aspect ratio $=1$ ) will not produce the same breakthrough curve as the $200 \mathrm{~mL}$ columns, but will prevent poor feed distribution and channelling and allow mathematical analys is of the breakthrough curve. Longer columns will be required to replicate the performance of the $200 \mathrm{~mL}$ columns. A $15-\mathrm{cm}$ column is suggested for a flow of $6 \mathrm{cv} / \mathrm{hr}$ with NCAW. Higher flow rates will not require as long of column.

The $200 \mathrm{~mL}$ column in turn appears to produce breakthrough curves very similar to those that would be produced by the Hanford Tank Waste Remediation System (TWRS) baseline $2000 \mathrm{~L}$ ion exchange columns. However, if results identical to the $2000 \mathrm{~L}$ column are required, a $200 \mathrm{~mL}$ column may not be sufficient since there may be elements of film diffusion resistance in the $200 \mathrm{~mL}$ column that are not present in the $2000 \mathrm{~L}$ column. Further studies will be required to determine the minimum length to match the breakthrough curve of the $2000 \mathrm{~L}$ baseline column. 
TABLE S.1. Column Sizing

\begin{tabular}{||l|c|c|c||}
\hline & \multicolumn{3}{|c||}{ Minimum Column Size } \\
\hline & Volume, mL & Diameter, cm & Length, cm \\
\hline CS-100 & 5.4 & 1.9 & 1.9 \\
\hline R-F & 0.8 & 1 & 1 \\
\hline & \multicolumn{2}{|c|}{ Replicate Lab-scale Column Performance } \\
\hline CS-100 & 42 & 1.9 & 15 \\
\hline R-F & 12 & 1 & 15 \\
\hline \hline
\end{tabular}




\section{CONTENTS}

EXECUTIVE SUMMARY . . . . . . . . . . . . . . . . . . . . . . . . . . i i

1.0 INTRODUCTION . . . . . . . . . . . . . . . . . . . . . . . . . 1

1.1 BACKGROUND . . . . . . . . . . . . . . . . . . . 1

1.2 PURPOSE . . . . . . . . . . . . . . . . . . . . 1

1.3 SCOPE ........................ . . 2

1.4 APPROACH .............................. 2

2.0 PAST SCALE-UP STUDIES . . . . . . . . . . . . . . . . . 4

3.0 COLUMN DIAMETER AND SHAPE . . . . . . . . . . . . . . . . . 10

3.1 COLUMN DIAMETER . . . . . . . . . . . . . . . . . . 10

3.2 BED ASPECT RATIO . . . . . . . . . . . . . . . 11

4.0 COLUMN LENGTH . . . . . . . . . . . . . . . . . . . . . . 12

4.1 DISPERSION . . . . . . . . . . . . . . . . . 12

4.2 ENTRANCE LENGTH . . . . . . . . . . . . . . . . . . 16

4.3 DEVELOPING WAVE SHAPE . . . . . . . . . . . . . . . 17

4.4 MASS TRANSFER LIMITATIONS . . . . . . . . . . . . . . . . . 19

5.0 CONCLUSIONS . . . . . . . . . . . . . . . . . . . . 24

6.0 RECOMMENDED EXPERIMENTAL WORK . . . . . . . . . . . . . . . 26

7.0 REFERENCES . . . . . . . . . . . . . . . . . . . . . . . . . 28

APPENDIX A - COLUMN LOADING AND ELUTION MODEL 


\section{FIGURES}

1. Comparison of the Cesium Breakthrough Curves using $200 \mathrm{~mL}$ Columns with Simulated Waste and $17 \mathrm{~mL}$ Columns Using Actual Neutralized PUREX Waste at the Waste Valley Demonstration Project (Itzo 1987)

2. Comparison of Cesium Breakthrough Curves Using $200 \mathrm{~mL}$ Columns with Simulated Waste and the Full-Scale Columns Using Actual Neutralized PUREX Waste at the West Valley Demonstration Project (Kurath 1989)

3. Comparison of Cesium Breakthrough Curves with SRS Simulant Using a $2 \mathrm{~mL}$ at $3 \mathrm{cv} / \mathrm{hr}$ and several $200 \mathrm{~mL}$ Columns at $2 \mathrm{cv} / \mathrm{hr}$. (Bibler et al. 1990 and Bray et al. 1990)

4. Comparison of Cesium Breakthrough Curves Performed with 2 and 10 $\mathrm{mL}$ Columns and 101-AW Simulant at $10 \mathrm{cv} / \mathrm{hr}$. (Bibler 1994) . . .

5. Model Developed Cesium Breakthrough Curves for Columns of various Lengths. The Curves Display the Effects of Axial Dispersion on Column Breakthrough. Data at $1 \mathrm{cv} / \mathrm{hr}$ with NCAW and CS-100 Resin. .

6. Model Developed Cesium Elution Curve for Columns of Various Lengths. The Curves Display the Effects of Axial Dispersion on the Elution Curve. Data at $1 \mathrm{cv} / \mathrm{hr}$ with NCAW and CS-100 Resin. . .

7. Model Developed Cesium Breakthrough Curves for 5 Columns in Series. The Curves Display the Effects of Developing Wave Shape on the Column Breakthrough for $2 \mathrm{~cm}$ and $40 \mathrm{~cm}$ long Column. Data Shifted Back in Order to Align 50\% Breakthrough Points for A11 Columns. Data at $6 \mathrm{cv} / \mathrm{hr}$ for NCAW and CS-100 Resin. NOTE: Axial Dispersion Effects are Also Included in Model. . . . . . . . . . .

8. Model Developed Cesium Breakthrough Curves with CS-100 for Columns of Various Lengths. The Curves Display the Effects of Film Diffusion Mass Transfer Limitations (MTL) as Compared to Runs with Dispersive Effects Only. Data at $6 \mathrm{cv} / \mathrm{hr}$ with NCAW. . . . . . . .

9. Model Developed Cesium Breakthrough Curves with R-F for Columns of Various Lengths. The Curves Display the Effects of Film Diffusion Mass Transfer Limitations (MTL) as Compared to Runs with Dispersive Effects Only. Data at $6 \mathrm{cv} / \mathrm{hr}$ with NCAW.

\section{TABLES}

S.1. Column Sizing ......................... . . iv

1. Column Dimensions Studied . . . . . . . . . . . . . . . . . . . . . 14

2. Mass Transfer Coefficients . . . . . . . . . . . . . . . . 23 


\subsection{INTRODUCTION}

\subsection{BACKGROUND}

It is presently planned to remove cesium from Hanford tank waste supernates and sludge wash solutions using ion exchange. To support the development of a cesium ion exchange process, laboratory experiments produced column breakthrough curves using wastes simulants in $200 \mathrm{~mL}$ columns. These tests provided an understanding of the process rate and to a limited extent the equilibrium behavior. To verify the validity of the simulant tests, column runs with actual supernatants are being planned.

Significant costs are associated with obtaining, transporting, and testing radioactive waste samples. Use of the minimum possible column size requires less radioactive waste, fewer safety and dose considerations, and fewer waste-disposal concerns. However, if the test-columns are too small, the data obtained cannot be fully utilized and cannot ultimately be used to scale up to production scale columns.

\subsection{PURPOSE}

The purpose of these actual waste tests is two-fold. First, the tests will verify that use of the simulant accurately reflects the equilibrium and rate behavior of the resin compared to actual wastes. Batch tests and column tests will be used to compare equilibrium behaviors and rate behaviors, respectively. Second, the tests will assist in clarifying the negative interactions between the actual waste and the ion exchange resin, which cannot be effectively tested with simulant. Such interactions include organic fouling of the resin and salt precipitation in the column. These effects may affect the shape of the column breakthrough curve. The reduction in column size also may change the shape of the curve, making the individual effects even more difficult to sort out. To simplify the evaluation, the changes due to column size must be either understood or eliminated.

This report describes the determination of the column size for actual waste testing that best minimizes the effect of scale-down. This evaluation 
will provide a theoretical basis for the dimensions of the column.

Experimental testing is still required before the final decision can be made.

\subsection{SCOPE}

This evaluation will be confined to the study of CS-100 and R-F resins with NCAW simulant and to a limited extent DSSF waste simulant. Only the cesium loading phase has been considered.

\subsection{APPROACH}

To determine the minimum size of column appropriate for cesium ion exchange, several avenues will be pursued. First, past experimental work with various sized columns will be discussed. Both successful and unsuccessful column scale-down attempts will be investigated. Theoretical work will then be presented for the system in question here. To determine the minimum column size, two dimensions must be considered: column width and column length. The minimum column width will be chosen such that the effects of radial velocity and concentration gradients become negligible. The rationale behind the various rules of thumb for length to diameter ratio (aspect ratio) will be investigated in the context of small-column systems.

The minimum column length will be chosen such that the effect of dispersion, entrance lengths, and film diffusion mass transfer become negligible. The model of column operation used to investigate these effects includes dispersion and mass transfer terms. Its parameters are based on work done by Kurath and colleagues (1994) to experimentally fit the laboratoryscale $200 \mathrm{~mL}$ columns (See Appendix for description). Finally, a test plan will be proposed to validate the conclusions of this theoretical approach.

Information derived from the above approach suggests three sizes of columns: 1) the smallest from which equilibrium and mass transfer information can be derived without being skewed by such effects as channeling and radial gradients that cannot be modelled easily, 2) the size required to obtain results within experimental error of those produced with the $200 \mathrm{~mL}$ column, and 3) the size required to obtain results identical to the $2000 \mathrm{~L}$ TWRS baseline column. In Case 1, the breakthrough curves would to be used in 
conjunction with a model to compare with the $200 \mathrm{~mL}$ column simulant runs. The curves can also be used to understand column equilibrium behavior. In Case 2 , breakthrough curves can be compared directly between the actual waste column and the $200 \mathrm{~mL}$ column and will provide mass transfer differences between the simulated and actual waste. In Case 3, direct scale-up to the full sized column is possible if both are run at the same residence time $(\mathrm{cv} / \mathrm{hr})$. 


\subsection{PAST SCALE-UP STUDIES}

Small columns have been used successfully in the past to predict the behavior of larger scale columns for the West Valley Demonstration Project. Removing cesium from a waste that is similar to NCAW, researchers produced breakthrough curves from a $200 \mathrm{~mL}$ simulant column and a $17 \mathrm{~mL}$ actual waste column (Itzo 1987). Since the waste composition differed slightly between the two columns, there a shift in the location of the breakthrough curves, however, their slopes are nearly identical (Figure 1). Similarity in slope indicates that the columns have similar mass transfer characteristics and column scale-down was successful. When these same $200 \mathrm{~mL}$ column runs were compared to the full scale $1700 \mathrm{~L}$ column, the results were nearly identical (Figure 2). Therefore, even a $17 \mathrm{~mL}$ column could have been used to scale up the columns (Kurath 1989).

Another example of successful use of small ion exchangers to predict breakthrough curves was with Savannah River Site (SRS) simulant (Bibler, Wallace and Bray 1990). This waste is also very similar to NCAW. A $2 \mathrm{~mL}$ column $(0.9 \mathrm{~cm}$ diameter) was loaded at $3 \mathrm{cv} / \mathrm{hr}$ using $\mathrm{R}-\mathrm{F}$ resin. The breakthrough curve for this column is similar to those predicted theoretically. Using an identical waste composition and $2 \mathrm{cv} / \mathrm{hr}$, Bray (1990) produced 11 breakthrough curves with a $200 \mathrm{~mL}$ of column. These curves are compared in Figure 3 . Some of the $200 \mathrm{~mL}$ column breakthrough curves exhibited poor results. The reason has not been identified, but could be due to channelling. Those curves have not been included here. Although there is significant variability between Bray's and Bibler's data, the breakthrough curve from $2 \mathrm{~mL}$ column is very similar to the breakthrough of the larger columns and in some cases is more ideal. This results suggests once again that a small column can provide acceptable results.

Bibler also studied the much more concentrated 101-AW simulant (1994). Unlike the other experiments run, this simulant is a concentrated form of DSSF. Columns 2 and $10 \mathrm{~mL}$ in volume were operated at $10 \mathrm{cv} / \mathrm{hr}$ using R-F. resin (Figure 4). Unlike the other examples shown, the $2 \mathrm{~mL}$ column experienced a much earlier breakthrough than the $10 \mathrm{~mL}$ columns and appears to have a lower distribution coefficient. Since both columns were run at the same flow rate 


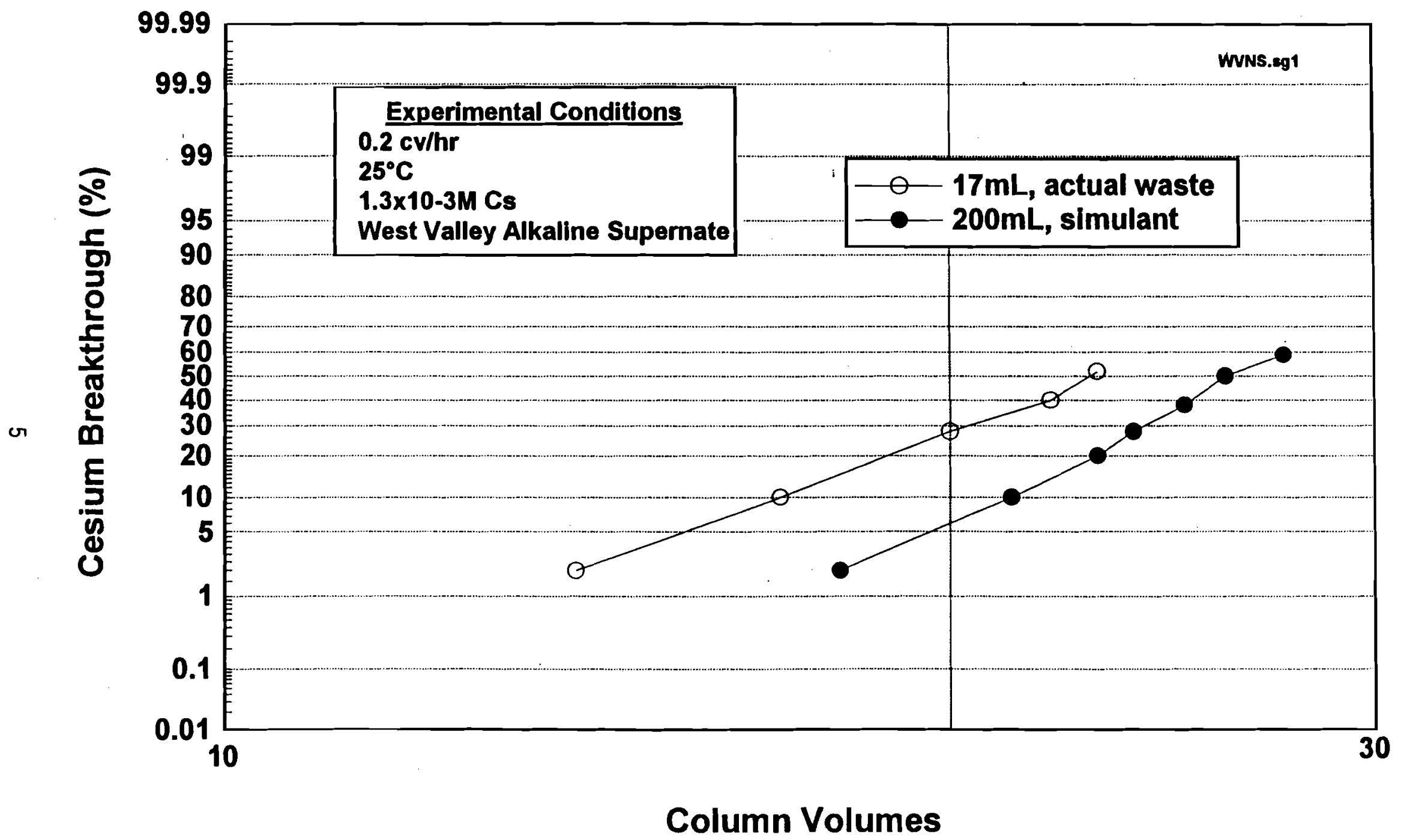

FIGURE 1. Comparison of the Cesium Breakthrough Curves using $200 \mathrm{~mL}$ Columns with Simulated Waste and $17 \mathrm{~mL}$ Columns Using Actual Neutralized PUREX Waste at the Waste Valley Demonstration Project (Itzo 1987) 


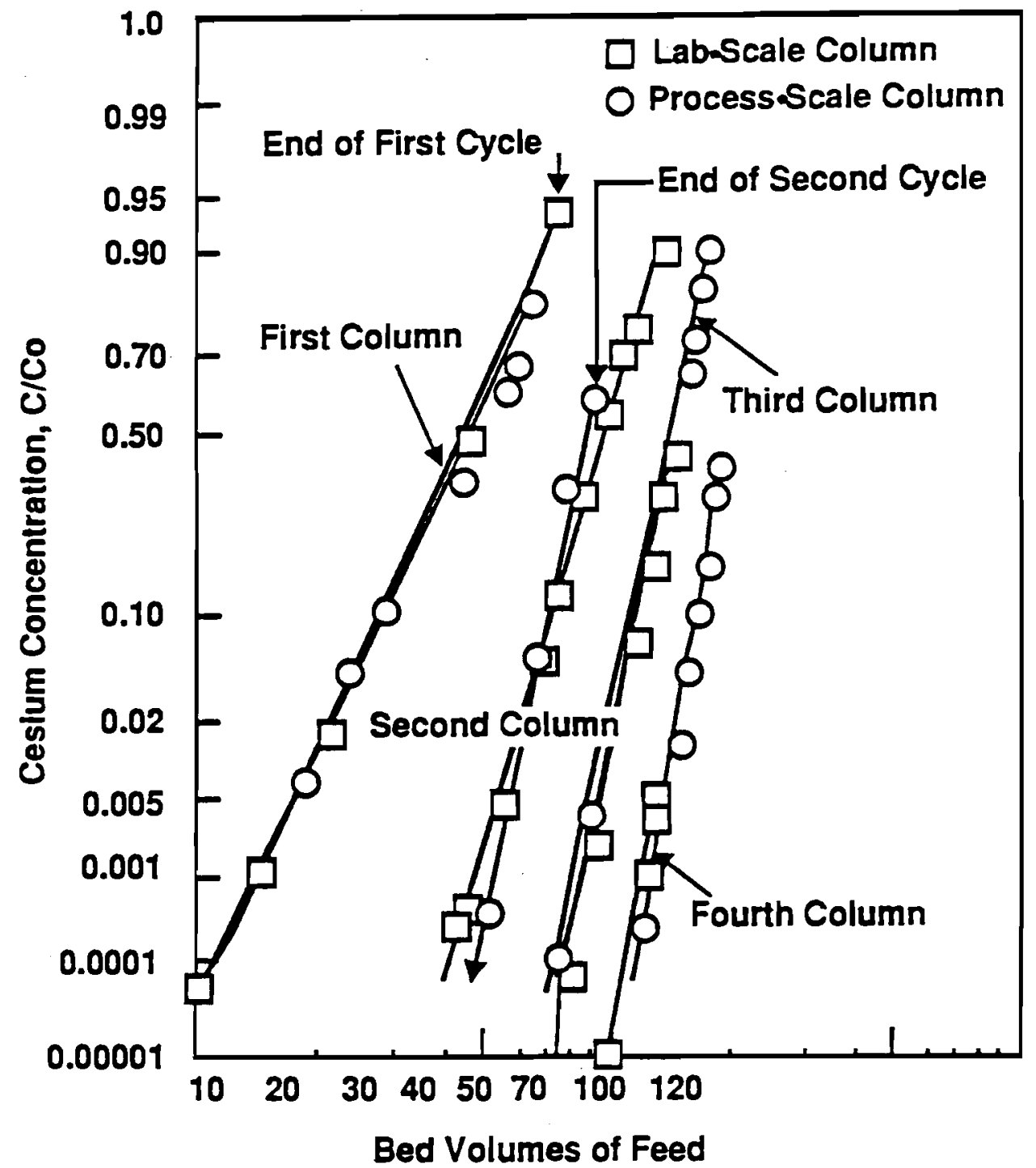

Fiqure 2. Comparison of Cesium Breakthrough Curves Using $200 \mathrm{~mL}$ Columns with Simulated Waste and the Ful1-Scale Columns Using Actual Neutralized PUREX Waste at the West Valley Demonstration Project (Kurath 1989) 


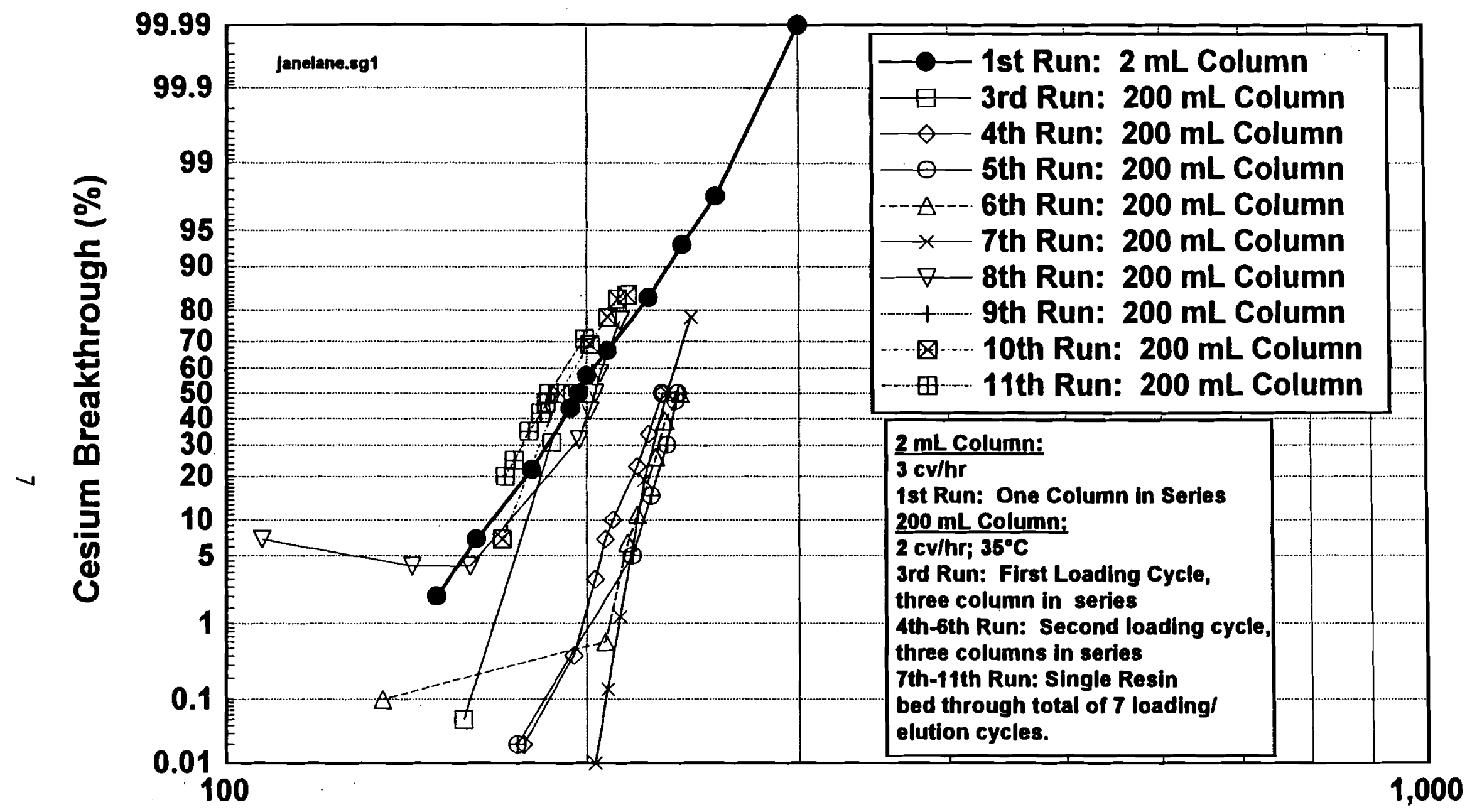

Column Volumes

Figure 3. Comparison of Cesium Breakthrough Curves with SRS Simulant Using a $2 \mathrm{~mL}$ at $3 \mathrm{cv} / \mathrm{hr}$ and several $200 \mathrm{~mL}$ Columns at $2 \mathrm{cv} / \mathrm{hr}$. (Bibler et al. 1990 and Bray et al. 1990) 


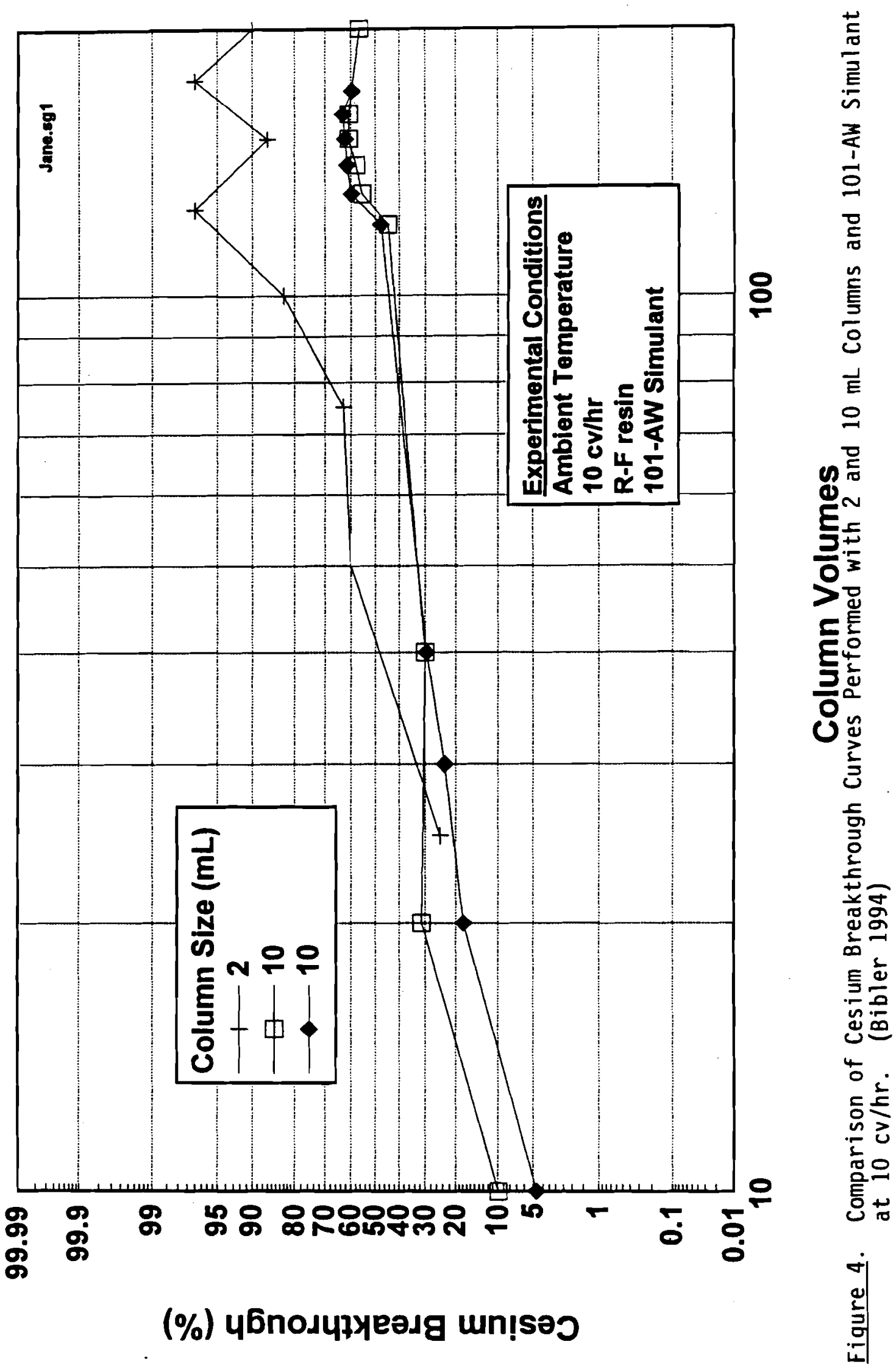


and with the same simulant, the difference must be the result of some nonideality associated with scale-down or channelling. The high flow rate may be responsible for these effects. In any case, scale-up may be difficult with a $2 \mathrm{~mL}$ column under these conditions. 


\subsection{COLUMN DIAMETER AND SHAPE}

Column diameter and shape are important considerations in preventing channelling and radial concentration and velocity gradients. Column diameter and shape will also impact the feed distribution in the column.

\subsection{COLUMN DIAMETER}

Column diameters of 20 to 30 particle diameters have been used as a standard for determining the minimum size for packed beds (Helfferich 1962; Smith 1981). These suggestions originally came from Schwartz and Smith (1953) and Fahien and Smith (1955). In a study to measure velocity variations in a packed bed, Schwartz and Smith found that the peak velocity occurs approximately 1 particle-diameter away from the pipe wall, due to increased void fraction near the wall. For columns of less than 30 particle diameters, the peak velocity is 30 to $100 \%$ higher than the velocity at the center of the column. Fahien and Smith studied radial variations in $\mathrm{CO}_{2}$ concentration in packed beds. They found that the Peclet number ${ }^{1}$ increases from the center towards the column wall. This increase is significant for columns less than 20 particle diameters.

Both these experiments were performed at Reynolds numbers between 10 and 1000; the actual waste columns will have Reynolds numbers of 0.001 to 0.1 . This difference may impact the use of 20-30 particle diameters as a method of determining column diameter. This is especially true since the literature work was performed in transition flow $(10<\operatorname{Re}<1000)$ and the small column work will be done in laminar flow (Re < 10). The applicability of these suggested diameters should be investigated.

If 30-particle-diameter columns are actually acceptable, a $1.0 \mathrm{~cm}$ diameter column could be used for the R-F resin $(0.34 \mathrm{~mm}$ mass-average diameter) and $1.9 \mathrm{~cm}$ in diameter column could be used for the CS-100 resin (0.63 $\mathrm{mm}$ mass-average diameter).

1 Defined as $d_{p} u_{0} / D_{r}$ where $d_{p}$ is the particle diameter, $u_{0}$ is the interstitial velocity, and $D_{r}$ is the radial dispersion. 


\subsection{BED ASPECT RATIO}

A "rule of thumb" developed by Helfferich et al. (1987) states that bed aspect ratios (length:diameter) should be 2 to 7 . For large columns, the aspect ratio may be as low as 1 . Columns with aspect ratios $<1$ tend to perform poorly because it is difficult to distribute the feed evenly over the area of the bed when the ratio is low. The tendency of feed to channel, especially down the middle of the column, will result in an under-utilized bed. For the smaller columns that will be used to process actual waste, a channel may constitute only a few poorly packed resin beads. Therefore, these correlations should continue to hold for the smaller columns and the minimum aspect ratio for the columns should be 1 .

The upper limit of the aspect ratio is controlled by the minimum column diameter, pressure drop, and structural considerations. As discussed above, the column diameter should not be less than 30 particle diameters. The maximum aspect ratio is also limited by the ability to construct a sturdy column which is very tall. Furthermore, as the bed aspect ratio increases, the pressure drop in the column also increases. 


\subsection{COLUMN LENGTH}

Four factors must be considered in determining the minimum column length: 1) cesium dispersion in the shorter column must not significantly change the shape of the breakthrough curves, 2) the column length must be sufficient to provide adequate mass transfer and hydrodynamic entrance length, 3) the column size should not affect the rate of formation of the constant wave shape, and (4) the velocity in the column must be large enough that limiting step of the mass transfer does not change during scale-down.

\subsection{DISPERSION}

Dispersion in a column is a combination of molecular diffusion and convective diffusivity. Both molecular and convective diffusion will cause a spread in the cesium concentration gradient as it moves through the resin beads. Dispersion will result in earlier breakthrough and a widening of the breakthrough curve. In the case of dispersion, the length of the columns is the significant parameter; column width has no effect. It is generally significant in very short columns with sharp breakthrough curves. Many investigators have studied dispersion in packed beds. A correlation was developed for dispersion using spherical particles at Reynolds numbers down to 0.003 (Chung and Wen, 1968):

$$
D_{a}=\frac{\epsilon d_{p} u_{0}}{0.2+0.011 R e_{p}^{0.48}}
$$

where

$$
\begin{aligned}
& D_{a} \quad=\text { the axial dispersion, } \\
& \varepsilon \quad=\text { the bed porosity, } \\
& d_{p} \quad=\text { the particle diameter, } \\
& u_{0} \quad=\text { the interstitial velocity, and } \\
& \operatorname{Re}_{p} \quad=\text { the Reynolds number in terms of the resin particles. }
\end{aligned}
$$

The breakthrough curve for CS-100 resin and NCAW simulant at $1 \mathrm{cv} / \mathrm{hr}$ and various column lengths (see Table 1) were compared to the 2000 L TWRS baseline column. The breakthrough curves for $15,20,40 \mathrm{~cm}$ long columns were very similar to that of the $2000-\mathrm{L}(136 \mathrm{~cm})$ column (see Figure 5). The shorter columns $(1,3,5$, and $10 \mathrm{~cm})$ successively deviated from the longer columns with the $1 \mathrm{~cm}$ column showing the greatest deviation. 

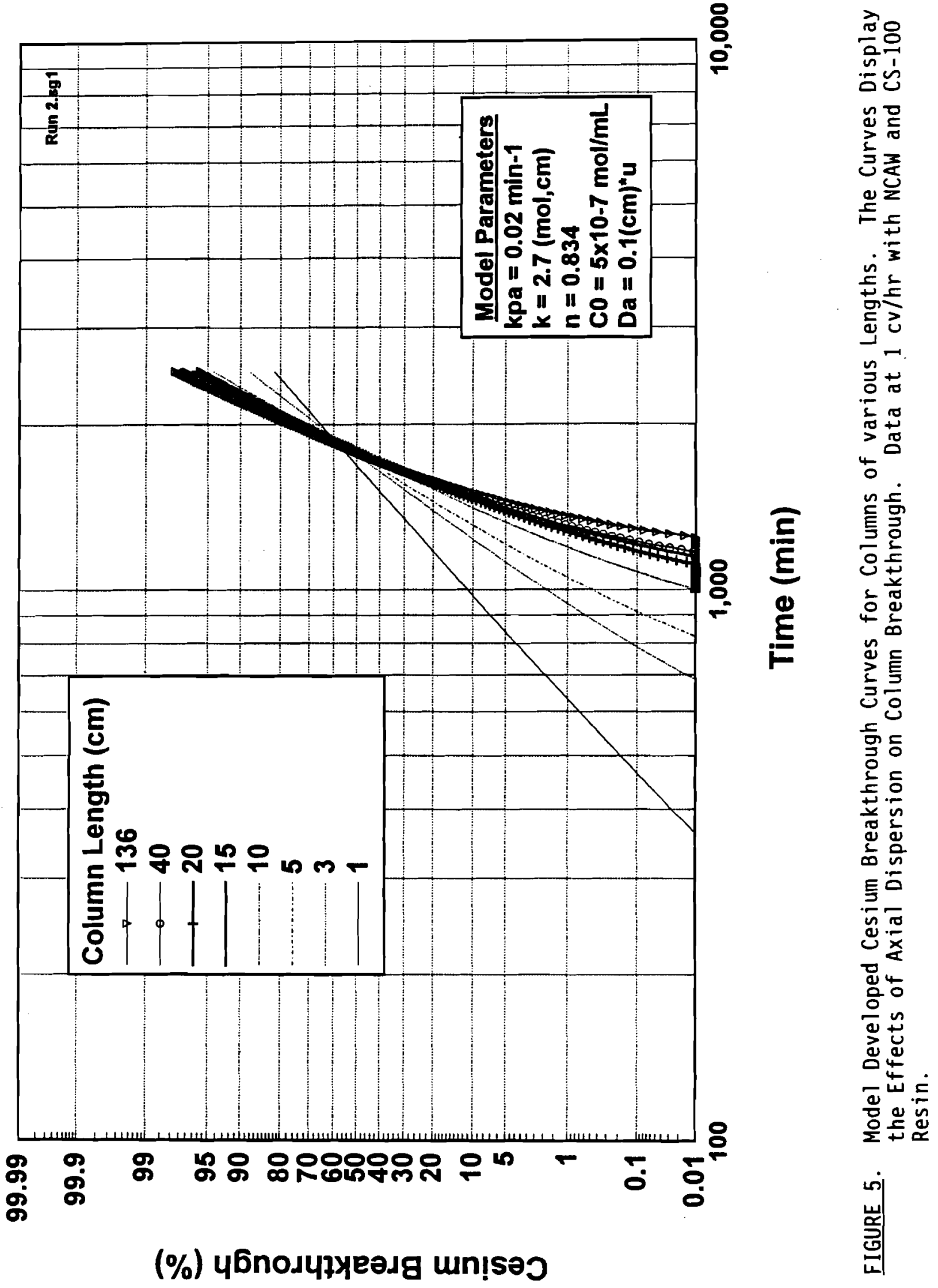
Flow rate, resin type, and waste type were varied to elucidate their effect on dispersion. Those variables have much less effect than column length on dispersion-induced spreading of the breakthrough curve. Decreasing flow rate increased the effect of dispersion. Similarly, loading waste with CS-100 increased the effect of dispersion over that found with R-F resin. Although the breakthrough curves for R-F and CS-100 with DSSF were much less sharp than those with NCAW the effects of dispersion as they relate to column scale-down were similar.

IABLE 1. Column Dimensions Studied

\begin{tabular}{|c|c|c|}
\hline $\begin{array}{c}\text { Col umn Length } \\
(\mathrm{cm})\end{array}$ & $\begin{array}{c}\text { Col umn Width } \\
(\mathrm{cm})\end{array}$ & $\begin{array}{c}\text { Col umn Volume } \\
(\mathrm{mL})\end{array}$ \\
\hline 1 & 1 & 1.6 \\
\hline 2 & 2 & 6.3 \\
\hline 3 & 2 & 9.4 \\
\hline 5 & 2 & 16 \\
\hline 10 & 2 & 31 \\
\hline 15 & 2.54 & 76 \\
\hline 20 & 2.54 & 100 \\
\hline 40 & 2.54 & 200 \\
\hline 136 & 136 & $2,000,000$ \\
\hline
\end{tabular}

Dispersion was also studied as it relates to elution. Since cesium retention is not favored during elution, the cesium concentration curve spreads as it moves down the column (a "non-sharpening" behavior). Therefore, the additional curve spreading due to dispersion is insignificant during elution (See Figure 6). Carberry and Wende1 (1963) investigated the effects of axial mixing. Their work suggests that axial dispersion should be negligible for a axial Peclet number of 2 as long as the bed depth exceeds 50 particle diameters. Lower Peclet numbers require longer beds. The axial Peclet number for NCAW is between 0.2 and 0.6 at the column conditions described here. 


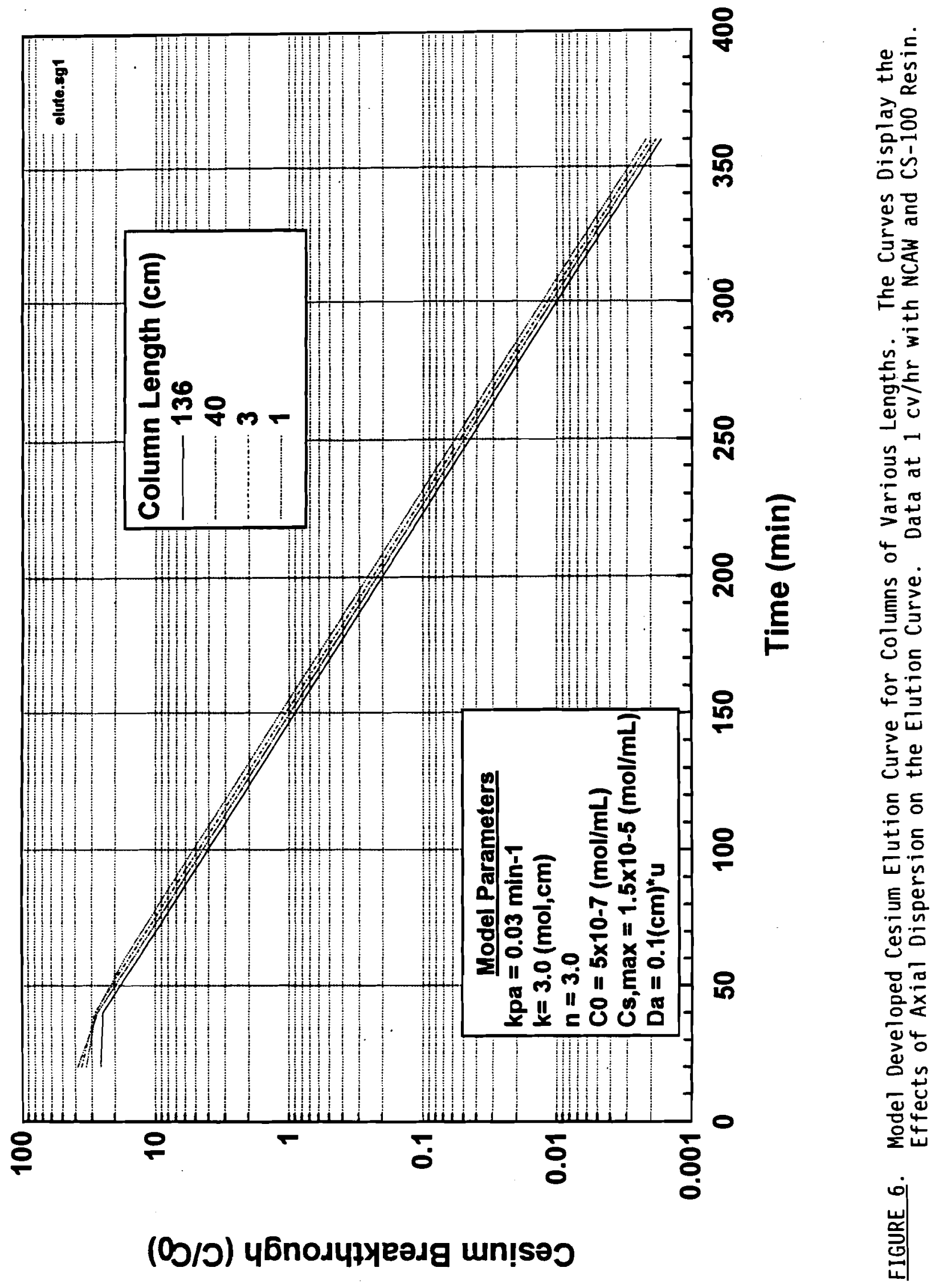


Therefore, the bed depth must be significantly greater than 50 particle diameters, which agrees with the work presented above.

\subsection{ENTRANCE LENGTH}

The hydrodynamic and diffusion entrance length must be much smaller than the bed length in a column. In the full scale column this is undoubtedly true. In order for the smaller column to duplicate the results of the larger, the entrance length of the smaller column must also be completely developed within a short distance into the column. If the Schmidt number ${ }^{2}$ is large (approximately $10^{3}$ for the wastes studied here), the hydrodynamics impact the cesium profile much more profoundly than does molecular diffusion. Therefore, the hydrodynamic entrance length should determine the rate of development for both the velocity) and the concentration profile. To determine the hydrodynamic entrance length for laminar flow in a tube, the following equation was developed (Incropera and Dewitt 1985):

$$
\left(\frac{x}{D}\right)=0.05 R e_{D}
$$

where $\operatorname{Re}=$ the Reynolds number of the circular tube,

$D=i$ ts diameter, and

$x=$ is the entry length.

Since this expression was not developed for a packed bed, two approaches can be taken: assume the entire column is the diameter for the entrance length $(D)$ or assume that the interparticle spacing is the diameter for calculating the entrance length. The most reasonable approach would be to assume that the entrance length is controlled by interparticle spacing. Assuming a $0.06 \mathrm{~cm}$ diameter spacing, NCAW viscosity of 2.6 centistokes, a $1 \mathrm{~cm}$ long column, and $12 \mathrm{cv} / \mathrm{hr}$ flow rate, the entrance length is calculated to be approximately 3 microns. This is much smaller than the column length and is the density, and $D$ is the diffusivity. It is the ratio of viscous and diffusive forces. 
would be even more insignificant for larger columns. Therefore, the entry length is not important in determining the length of the test columns.

\subsection{DEVELOPING WAVE SHAPE}

As cesium loads on an ion exchange column, a concentration gradient forms in the column. This concentration gradient wave is originally sharp, but tends to spread as it moves down the column. If equilibrium favors the loading of cesium onto the resin, once this wave is established, it will not change in width or shape. If the isotherm is very favorable, the curve will approach a constant wave shape very quickly. If however, the separation factor is not large, the exchanger mass transfer is quite slow, or the flow rate is high, the constant wave shape will develop more slowly. It may not develop before exiting the first column, and it in fact may require several columns in series (or one very long column) to reach the constant wave shape.

To determine if the scale of the column affects this development of a constant wave shape, the model was run for 5 ion-exchange columns in series to track the changing shape of the breakthrough curve. A $2 \mathrm{~cm}$ long column series was compared to a $40 \mathrm{~cm}$ long column series. CS-100 resin and NCAW simulant were used at a flow rate of $6 \mathrm{cv} / \mathrm{hr}$. In order to compare these column series, all the breakthrough curves were shifted back in time so that the $50 \%$ breakthrough point for each column is aligned.

As shown in Figure 7 , neither the $2 \mathrm{~cm}$ nor the $40 \mathrm{~cm}$ long column has completely reached equilibrium after the first column. In fact, the columns approach equilibrium only after $>5$ columns. Both the large and small column series show similar trends, indicating that the formation of a constant wave shape is independent of column size. The small difference between the two sizes of column is believed to be only a function of dispersion. Therefore, the attainment of the constant wave shape is not a concern with regard to scale-down. At this flow rate, even the full-scale column will require multiple columns to reach a constant wave shape. 


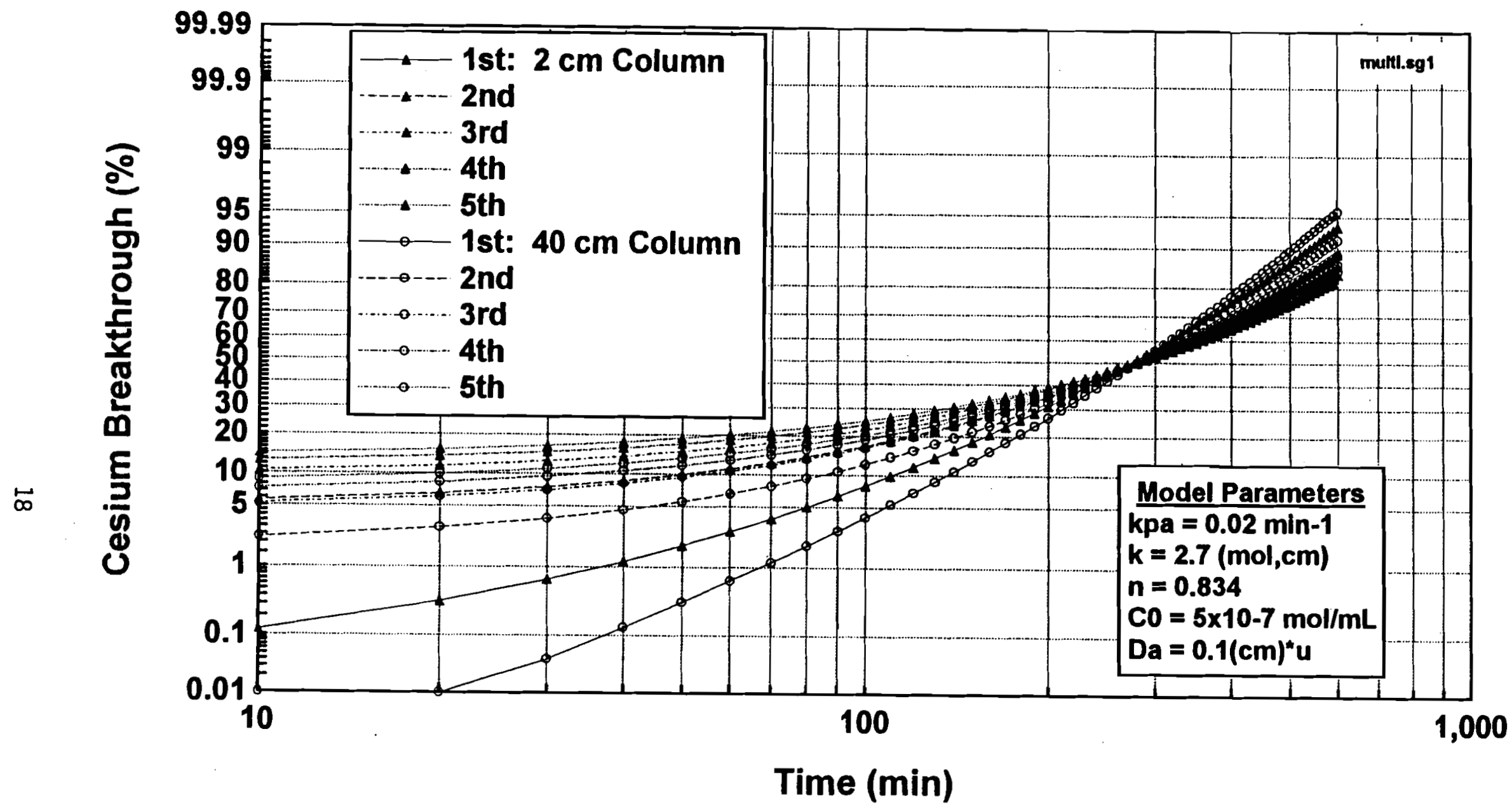

FIGURE 7. Model Developed Cesium Breakthrough Curves for 5 Columns in Series. The Curves Display the Effects of Developing Wave Shape on the Column Breakthrough for $2 \mathrm{~cm}$ and $40 \mathrm{~cm}$ long Column. Data Shifted Back in Order to Align 50\% Breakthrough Points for All Columns. Data at $6 \mathrm{cV} / \mathrm{hr}$ for NCAW and CS-100 Resin. NOTE: Axial Dispersion Effects are Also Included in Model. 


\subsection{MASS TRANSFER LIMITATIONS}

At high fluid velocities, the rate of ion exchange in a column is controlled by diffusion of cesium in the particle phase. As a column is scaled down at constant residence time, superficial velocity is reduced. When the velocity surrounding the particles is reduced, the concentration boundary layer around the particles increases and ionic diffusion from the bulk solution to the particle surface becomes increasingly more important. At very low velocities, the mass transfer due to film diffusion may control the rate of ion exchange. To determine the influence of these two factors, the mass transfer coefficient for film and particle diffusion, respectively were calculated using the following correlations:

$$
\begin{gathered}
k_{f} a=\frac{2.62(D v)^{0.5}}{d^{1.5}} \\
k_{p} a=\frac{60 D_{p}}{d_{p}^{2}}
\end{gathered}
$$

In these correlations,

$$
\begin{array}{ll}
D & =\text { the diffusivity in the liquid, } \\
D_{p} & =\text { the diffusivity in the solid phase, } \\
v & =\text { the superficial velocity, and } \\
d_{p} & =\text { the particle diameter (Perry and Chilton, 1973). }
\end{array}
$$

Using the sum of their resistances, an overall mass transfer coefficient can be determined.

The diffusivity of cesium in the liquid and solid phase are two parameters that must be determined. The liquid diffusivity was assumed to be constant with respect to ionic concentration. A value of $1.2 \times 10^{-3} \mathrm{~cm}^{2} / \mathrm{min}$ was used based on the self-diffusivity of potassium in a $4 M$ solution of $K C 1$ (Bruins 1929). The particle-phase diffusivity of the resins was determined in one of two ways: 1) batch kinetic tests performed at Sandia National Laboratory (SNL) and PNL (unpublished data) and 2) fitting column tests 
performed at PNL (Kurath et a1. 1994). In both cases it must be assumed that particle diffusion limits mass transfer. Values of $2 \times 10^{-7} \mathrm{~cm}^{2} / \mathrm{min}$ and $1.4 \times 10^{-6} \mathrm{~cm}^{2} / \mathrm{min}$ were used for NCAW simulant on R-F and CS-100, respectively.

The mass transfer coefficient for film, particle and overall mass transfer coefficient were calculated for CS-100 and R-F resins with NCAW simulant (Table 2). These results shown that the importance of film diffusion varies inversely with column size. The $2000 \mathrm{~L}$ column has no film diffusion influences while film diffusion limitations significantly impact the mass transfer in the small column. Breakthrough curves modelled from these mass transfer coefficients are compared to the conditions without film diffusion limitations (deviation is caused only by dispersion). Figure 8 shows the breakthrough curve for CS -100 with NCAW at a flow rate of $6 \mathrm{cv} / \mathrm{hr}$. Figure 9 shows the breakthrough curve for R-F resin (also $6 \mathrm{cv} / \mathrm{hr}$ ). Because the effects of dispersion and mass transfer on the curves are similar (steeper breakthrough curve with increasing column length), they will be difficult to separate. In both cases, dispersion appears to have a larger effect on the slope of the breakthrough curve than film diffusion limitations.

If these calculations are correct, a $15 \mathrm{~cm}$ long column will produce breakthrough curves that are probably within experimental error of the fullscale column. If results identical to the full scale column are required, even the $40 \mathrm{~cm}$ column $(200 \mathrm{~mL})$ used in previous studies would not be sufficient since both dispersion and mass transfer continues to affect the shape of the breakthrough curve.

It not clear what impact DSSF will have on the required size of the ion exchange column. As mentioned previously, the effects of dispersion should be similar for both DSSF and NCAW. Preliminary results for Kurath (1994) seem to indicate that film diffusion could be more significant than particle diffusion for DSSF. Theoretically, this should not be the case since the chemical and physical properties of DSSF are not very different from those of NCAW. If DSSF is indeed limited by film diffusion, larger columns would be required for DSSF than NCAW in order to obtain results similar to the full scale column. Further experimental work should be performed to address this discrepancy. 


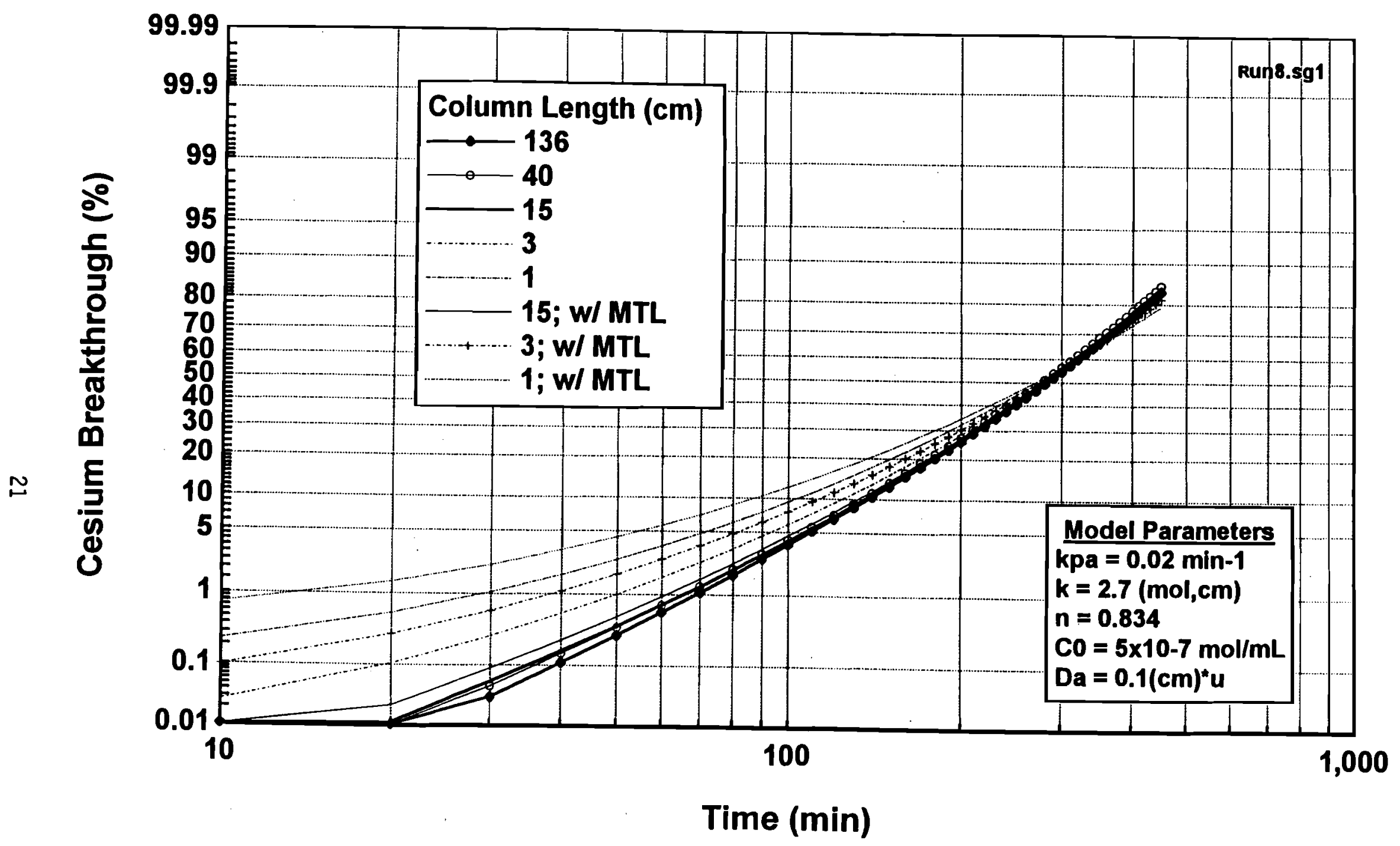

FIGURE 8. Model Developed Cesium Breakthrough Curves with CS-100 for Columns of Various Lengths. The Curves Display the Effects of Film Diffusion Mass Transfer Limitations (MTL) as Compared to Runs with Dispersive Effects Only. Data at $6 \mathrm{cv} / \mathrm{hr}$ with NCAW. 


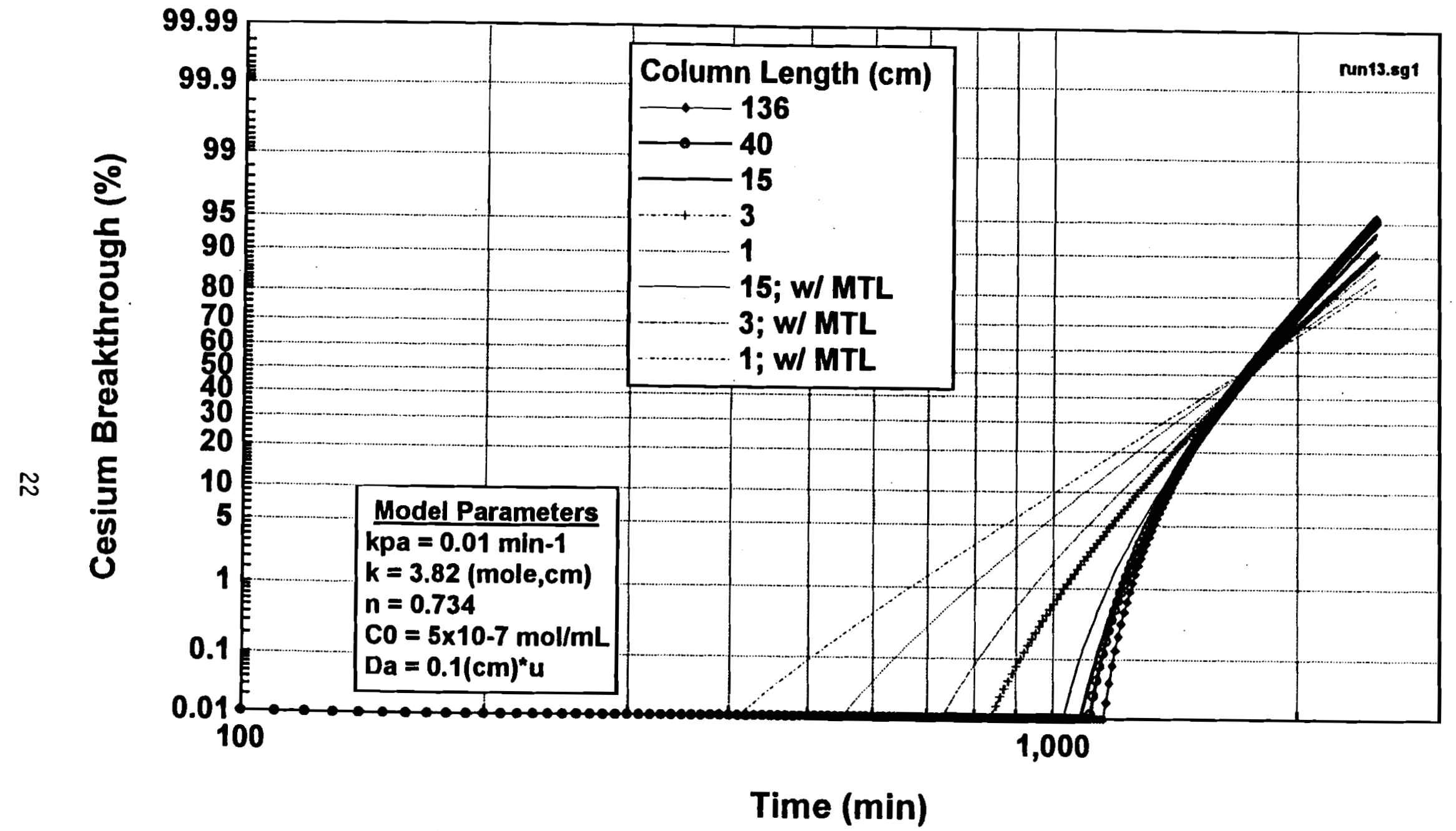

FIGURE 9. Model Developed Cesium Breakthrough Curves with R-F for Columns of Various Lengths. The Curves Display the Effects of Film Diffusion Mass Transfer Limitations (MTL) as Compared to Runs with Dispersive Effects Only. Data at $6 \mathrm{cv} / \mathrm{hr}$ with NCAW. 
TABLE 2. Mass Transfer Coefficients

\begin{tabular}{||l|c|c|c|c|}
\hline \hline & $K_{p} \mathrm{a}\left(\mathrm{min}^{-1}\right)$ & $\left.K_{f} \mathrm{a} / \lambda_{1}\right)\left(\mathrm{min}^{-}\right.$ & $\begin{array}{c}\text { Overal1 } \\
\left(\mathrm{min}^{-1}\right)\end{array}$ & $\begin{array}{c}\text { \% Film } \\
\text { Diffusion }\end{array}$ \\
\hline \multicolumn{5}{|c|}{$\mathrm{CS}-100$} \\
\hline $136 \mathrm{~cm}$ & 0.021 & 6.72 & 0.021 & 0 \\
\hline $40 \mathrm{~cm}$ & 0.021 & 0.348 & 0.020 & 6 \\
\hline $15 \mathrm{~cm}$ & 0.021 & 0.174 & 0.019 & 11 \\
\hline $2 \mathrm{~cm}$ & 0.021 & 0.124 & 0.018 & 19 \\
\hline $1 \mathrm{~cm}$ & 0.021 & 0.088 & 0.017 & 0 \\
\hline \multicolumn{5}{|c|}{$\mathrm{R}-\mathrm{F}$} \\
\hline $136 \mathrm{~cm}$ & 0.010 & 2.46 & 0.010 & 8 \\
\hline $40 \mathrm{~cm}$ & 0.010 & 0.127 & 0.0096 & 12 \\
\hline $15 \mathrm{~cm}$ & 0.010 & 0.079 & 0.0092 & 19 \\
\hline $2 \mathrm{~cm}$ & 0.010 & 0.045 & 0.0084 & 24 \\
\hline $1 \mathrm{~cm}$ & 0.010 & 0.032 & 0.0079 & \\
\hline \hline
\end{tabular}

* For $6 \mathrm{cv} / \mathrm{hr}$, NCAW simulant. 


\subsection{CONCLUSIONS}

Based on the above analysis, obtaining a breakthrough curve from which equilibrium and limited mass transfer information can be derived requires that the width of the column should be at least 30 particle diameters. This diameter should prevent channelling and reduce the radial concentration and velocity gradients. To prevent significant impact due to poor feed distribution, the column aspect ratio should be approximately 1 . Thus the minimum column diameter and height are $1 \mathrm{~cm}(0.78 \mathrm{~mL})$ for $\mathrm{R}-\mathrm{F}$ resin and $1.9 \mathrm{~cm}$ $(5.4 \mathrm{~mL})$ for $\mathrm{CS}-100$.

These are the minimum allowable column sizes. The breakthrough from these columns should provide information about the equilibrium behavior of the actual waste and the effects of organics and precipitation in the column feed. With modeling and experimentally determined dispersion and diffusion coefficients, these breakthrough curves may be successfully compared to the results obtained with the $200 \mathrm{~mL}$ column and the mass transfer coefficients determined.

To obtain breakthrough curves that replicate the performance of the $200 \mathrm{~mL}$ column, a slightly larger column would be required. Such a column would permit comparison of the resin mass transfer using actual waste with the simulant, in addition to the effects described above. Based on the results of this analysis, a $15 \mathrm{~cm}$ long column may be sufficient to provide such data for NCAW at $6 \mathrm{cv} / \mathrm{hr}$. Higher flow rate would allow a slightly smaller column, and lower flow rates would require a slightly larger column. At the minimum diameter to prevent channelling, a $12-\mathrm{mL}$ column can be used with $R-F$ and a $42-\mathrm{mL}$ column with CS-100.

If a breakthrough curve is required that is identical to the $2000 \mathrm{~L}$ column proposed by TWRS, the effects of dispersion and film mass transfer in the column must be negligible. In this case, even the $200 \mathrm{~mL}$ column studied previously may not be large enough to eliminate these effects.

The above work has focused on NCAW. DSSF, al though chemically quite similar to NCAW, appears to have a much slower rate of ion exchange. To 
resolve concerns and correctly propose a column size for DSSF further experimental work is required. 


\subsection{RECOMMENDED EXPERIMENTAL WORK}

The theoretical treatment presented herein should provide a starting point for the experimental work to verify the correct column size. Since most of the theoretical work was done with NCAW simulant and significant ion exchange data exists for NCAW, the initial experimental work should use this simulant. The initial flow rate should be $6 \mathrm{cv} / \mathrm{hr}$ to correspond to the results of this study. A decision should be made as to whether the column tests should give a well-formed curve (significant elements of film diffusion as the rate controlling step), breakthrough similar to a $200 \mathrm{~mL}$ column (elements of both film and particle controlled mass transfer), or a breakthrough curve identical to the $2000 \mathrm{~L}$ column (primarily or exclusively particle diffusion controlled mass transfer). Studies should also be performed on DSSF simulant. A similar approach to those used for NCAW should be taken, al though the flow rate should be reduced to $3 \mathrm{cv} / \mathrm{hr}$ to obtain improved breakthrough curves.

To verify the column size required for a well formed breakthrough, the experimental work should include the following:

- The column diameter should be a minimum of 30 particle diameters. This corresponds to $>1 \mathrm{~cm}$ for R-F resin and $>1.9 \mathrm{~cm}$ for CS-100. For conservatism during initial tests, larger diameters can be used to assure no channelling is occurring.

- During initial testing, the height of the resin in the column should be not less than the column diameter. To further prevent channelling, the resin bed should be as uniform as possible and be backwashed prior to use.

- If the distribution coefficients are much lower than expected, channeling is probably occurring and diameter and length of the column should be increased. If the slope of the breakthrough curve is unacceptably low, the column length should be increased.

- If the breakthrough curve is identical to that of the $200 \mathrm{~mL}$ column, the column length and diameter should be reduced proportionally to determine the minimum column size.

To verify the column size required for breakthrough that replicates the performance of the $200 \mathrm{~mL}$ column, the experimental work should include the following: 
- The column diameter should be a minimum of 30 particle diameters. This corresponds to $>1 \mathrm{~cm}$ for $\mathrm{R}-\mathrm{F}$ resin and $>1.9 \mathrm{~cm}$ for $\mathrm{CS}-100$. For conservatism during initial tests, larger diameters can be used to assure no channelling is occurring.

- The height of the resin in the column should initially be tested at 15 $\mathrm{cm}$ for both CS-100 and R-F resins.

- If the breakthrough curve is well formed but has a lower slope than the 200-mL column curve, use progressively longer columns up to the bed height of the proposed full-scale unit to identify the point at which the results are approach those of the $200 \mathrm{~mL}$ and the $2000 \mathrm{~L}$ column

- If the breakthrough curve is identical to that of the $200 \mathrm{~mL}$ column, reduce the length progressively to identify the minimum column length. 


\subsection{REFERENCES}

Bibler, J. P., R. M. Wallace, and L. A. Bray, "Testing a New Cesium-Specific Ion Exchange Resin for Decontamination of Alkaline High-Activity Waste," For presentation at the 1990 Waste Management Meeting, Tucson, AZ, February 25 March 1, 1990.

Bibler, J. P., 1994. "Year-End Report for UST: Cesium Extraction Testing Project D0E/DT\&E TTP No. SR1-03-20-01 (U), " WSRC-RP-94-146, Westinghouse Savannah River Company, Aiken, South Carolina.

Bray, L. A., R. J. Elovich, K. J. Carson, "Cesium Recovery using Savannah River Laboratory Resorcinol Formaldehyde Ion Exchange Resin," PNL-7273, Pacific Northwest Laboratory, Richland, Washington.

Bruins, H. R. 1929. "Coefficients of Diffusion in Liquids" International Critical Tables of Numerical Data, Physics, Chemistry, and Technology. Edward W. Washburn, ed., Vol. 5, McGraw-Hill Book Company, New York, pp. 63-76.

Carberry, James J. and Martin M. Wende1, 1963. "A Computer Model of the Fixed Bed Catalytic Reactor: The Adiabatic and Quasi-adiabatic Cases," AIChE Journal. Vol. 9, No. 1, pp. 129-133.

Chung, S. F. and C. Y. Wen, 1968. "Longitudinal Dispersion of Liquid Flowing Through Fixed and Fluidized Beds." AIChE Journal. Vol 14, No. 6, pp. 857866 .

Fahien, R. W. and J. M. Smith, 1955. "Mass Transfer in Packed Beds," AIChE Journal. Vol. 1, No. 1, pp. 28

Helfferich, Friedrich G., et al. 1987. Text from the AIChE Today Series, "Ion Exchange Theory and Practice." American Institute of Chemical Engineers. New York.

Incropera, Frank P. and David P. DeWitt, 1985. Fundamentals of Heat and Mass Transfer. 2nd Ed. John Wiley \& Sons. New York.

Itzo, R. F., 1987. "Integrated Checkout of the Supernatant Treatment System," WVNS-TR-50-001, West Valley Nuclear Services Company, West Valley, New York.

Kurath, D. D., L. A. Bray, W. A. Ross, D. K. Ploetz, "Correlation of Laboratory Testing and Actual Operations for the West Valley Supernatant Treatment System," PNL-SA-16871, Pacific Northwest Laboratory, Richland, Washington.

Kurath, D. E., L. A. Bray, K. P. Brooks, G. N. Brown, S. A. Bryan, C. D. Carlson, K. J. Carson, J. R. DesChane, R. J. Elovich, A. Y. Kim, 1994, "Experimental Data and Analysis to Support the Design of an. Ion Exchange Process for the Treatment of Hanford Tank Waste Supernatant Liquids," TWRSPP94-010, Pacific Northwest Laboratory, Richland, WA. 
Perry, R. H., C. H. Chilton, 1973. Chemical Engineers Handbook. Fifth Ed. McGraw-Hi11, Inc. New York, New York.

Schwartz, C. E. and J. M. Smith, 1953. "Flow Distribution in Packed Beds," Industrial and Engineering Chemistry. Vol. 45, No. 6, pp. 1209-1218.

Smith, J. M., 1981. Chemical Engineering Kinetics. 3rd Ed. McGraw-Hill, Inc. New York, New York. 
APPENDIX A

COLUMN LOADING AND ELUTION MODEL 


\section{APPENDIX A}

\section{COLLUMN LOADING AND ELUTION MODEL}

The column loading model was developed and input into Simusolv" (Dow Chemical) code by Dr. R. S. Skeen, PNL. The code was modified and used to analyze the ion-exchange column loading data and investigate elution behavior. The assumptions, governing equations, and boundary conditions are summarized below.

The Simusolv" model treats the ion-exchange as an adsorption/desorption process characterized by an equilibrium isothem. For analysis of the column loading data, the Freundlich isotherm was used. The ion-exchange kinetics are accounted for by a linear driving force between the cesium concentration in the solid and the equilibrium concentration of cesium in the solid. The mass transfer coefficient and flowrate are assumed constant, and temperature variations are assumed negligible. The model also incorporates dispersion in the liquid phase. The dispersion coefficient is calculated from a correlation based on the Peclet number, particle size, and fluid velocity (Perry's Chemical Enqineers' Handbook, 6th ed., p. 16-27).

I. Constants and Variables

$C_{A}=1$ iquid cesium concentration $(\mathrm{mol} / \mathrm{ml})$

$C_{A s}=$ solid cesium concentration (mol/cc)

$t=$ time (min)

$z=$ distance from column entrance $(\mathrm{cm})$

$U_{z}=$ liquid velocity $(\mathrm{cm} / \mathrm{s})$

$\varepsilon=$ void fraction

$D_{A}=$ effective dispersion coefficient $\left(\mathrm{cm}^{2} / \mathrm{s}\right)$

$C_{A_{0}}=$ feed cesium concentration. (mol/ml)

$C_{A s}{ }^{*}=$ equilibrium cesium concentration in the solid (mol/cc)

$C_{A s, \max }=$ solid cesium concentration in equilibrium with $C_{A_{0}}$ (mol/cc)

$\mathrm{K}_{\mathrm{p}} \mathrm{a}=$ particle phase mass transfer coefficient $\left(\mathrm{min}^{-1}\right)$

$L=$ column height $(\mathrm{cm})$ 


$$
\begin{aligned}
& K=\text { Freund } 7 i c h \text { coefficient } \\
& N=\text { Freund } 7 i c h \text { exponent }
\end{aligned}
$$

II. Mass Balance on Cesium

$$
\frac{\partial C_{A}}{\partial t}+U_{z} \frac{\partial C_{A}}{\partial z}+\frac{1-\epsilon}{\epsilon} \frac{\partial C_{A s}}{\partial t}=D_{A} \frac{\partial^{2} C_{A}}{\partial z^{2}}
$$

III. Adsorption of Cesium

$$
\frac{\partial C_{A s}}{\partial t}=K_{P} a\left(C_{A S}^{\cdot}-C_{A S}\right)
$$

IV. Equilibrium Model (Freundlich isotherm)

$$
C_{A s}=K C_{A}^{N}
$$

v. Boundary Conditions

$$
\begin{aligned}
& \text { 1. }-D_{A} \frac{\partial C_{A}}{\partial z}+U_{Z} C_{A}=U_{Z} C_{A 0} \text { at } z=0 \text { for all } t \\
& \text { 2. } \frac{\partial C_{A}}{\partial z}=0 \text { at } z=L \text { for all } t
\end{aligned}
$$

VI. Initial Condition

$$
\begin{aligned}
& C_{A}=0 \text { for } 0<z \leq L \text { at } t=0 \\
& C_{A s}=0 \text { for } 0<z \leq L \text { at } t=0
\end{aligned}
$$

VII. Model Assumptions

1. Ion-exchange is governed by a linear driving force between the cesium concentration in the solid and the equilibrium cesium concentration in the solid.

2. The mass transfer coefficient is constant. 
3. The flowrate is constant.

4. The equilibrium behavior can be described by the Freundlich isotherm.

5. Dispersion coefficient is a linear function of liquid velocity.

6. Temperature variations are negligible.

VIII. Parameters Used In Study

TABLE A.1. Model Parameters Used

\begin{tabular}{||c|c|c|c|c||}
\hline & \multicolumn{2}{|c|}{ NCAW } & \multicolumn{2}{c|}{ DSSF } \\
\cline { 2 - 5 } & $\mathrm{CS}-100$ & $\mathrm{R}-\mathrm{F}$ & $\mathrm{CS}-100$ & $\mathrm{R}-\mathrm{F}$ \\
\hline $\mathrm{Kp} \mathrm{a}\left(\mathrm{mi} \mathrm{n}^{-1}\right)$ & 0.02 & 0.01 & 0.012 & 0.002 \\
\hline $\mathrm{D}_{\mathrm{A}}\left(\mathrm{cm}^{2} / \mathrm{min}\right)$ & 0.1 & 0.1 & 0.1 & 0.1 \\
\hline $\mathrm{K}(\mathrm{mol}, \mathrm{mL})$ & 2.7 & 3.82 & 2.3 & 2.08 \\
\hline $\mathrm{N}$ & 0.834 & 0.734 & 0.834 & 0.734 \\
\hline$C_{\text {A0 }}(\mathrm{mol} / \mathrm{mL})$ & \multicolumn{2}{|c|}{$5 \times 10^{-7}$} & \multicolumn{2}{|c|}{$7 \times 10^{-8}$} \\
\hline \hline
\end{tabular}

